\title{
Early malperfusion, ischemia reperfusion injury, and respiratory failure in acute complicated type $B$ aortic dissection after thoracic endovascular repair
}

\author{
Jiang Xiong, Minhong Zhang, Wei Guo*, Xiaoping Liu, Tai Yin, Xin Jia, Hongpeng Zhang, Yongle Xu \\ and Lijun Wang
}

\begin{abstract}
Background: The aim of this study was to determine the early mortality and major complications of acute complicated type B aortic dissection (ACBD) after thoracic endovascular aortic repair (TEVAR).

Methods: Twenty-six consecutive patients with ACBD who underwent TEVAR were included. Clinical indications before TEVAR and in-hospital mortality and major complications after TEVAR were analyzed and compared with similar reports.

Results: TEVAR was technically successful in all cases. In-hospital mortality occurred in four patients (15\%), and major complications occurred in an additional four patients (15\%). Three of the four (75\%) of the deaths were associated with malperfusion and ischemia reperfusion injury (IRI), and 3/4 (75\%) of the major complications were caused by respiratory failure (RF).

Conclusions: In-hospital mortality associated strongly with severe end-organ malperfusion and IRI, while major complications associated with RF, during TEVAR. Our results indicate that malperfusion, IRI and respiratory failure during TEVAR should be carefully monitored and aggressively treated.
\end{abstract}

\section{Background}

Thoracic endovascular aortic repair (TEVAR) is the promising treatment for acute complicated type B aortic dissection (ACBD) [1-4]. During the acute phase of the dissection, TEVAR can obviate impending aortic rupture and relieve dynamic malperfusion [5,6]. A delayed benefit is potentiation of thrombosis within the thoracic false lumen, thereby mitigating the risk of aneurysmal dilatation and subsequent aortic rupture [7-9]. TEVAR is superior to conventional surgical repair, which is more invasive and has more potential complications.

Despite the short-term benefits (low morbidity and mortality) of TEVAR for the repair of ACBD [1,4], an increasing number of studies report early mortality and major complications after TEVAR [7,10-12]. Major

\footnotetext{
* Correspondence: pla301dml@vip.sina.com

Departments of Vascular Surgery, Clinical Division of Surgery, Chinese PLA General Hospital, Beijing, China
}

complications of TEVAR include permanent renal failure, stroke, paraplegia, and respiratory failure (RF). An analysis of early mortality and major complications, with the exclusion of procedure-related factors, would provide a better understanding of the impact of TEVAR on ACBD outcomes and provide insight in the clinical decisions of when to use TEVAR and when to add adjuvant therapy to the TEVAR procedure. Therefore, this study focused on ACBD patients to identify indicators that could predict in-hospital mortality or major complications during TEVAR.

\section{Methods \\ Patients}

From March 2004 to October 2010, 26 consecutive patients with ACBD underwent TEVAR in our department. TEVAR was performed less than 14 days after the onset of symptoms in all cases. The clinical characteristics 
of the patients are listed in Table 1. All the patients had confirmed Stanford type B dissection by computed tomography (CT) angiography. ACBD was diagnosed according to the signs and symptoms, including severe end-organ malperfusion, persistent pain, acute aortic failure, refractory hypertension and encephalopathy.

\section{Techniques}

Before the endovascular procedure, CT angiography was used to measure the distance and diameter of the landing zone, which is the normal part of the aorta used to attach the stent graft during the TEVAR procedure. During the procedure, the landing zone diameter was determined by digital subtraction angiography. The diameter of the selected stent graft was $10-20 \%$ larger than the landing zone diameter. All procedures were performed in an angiography unit (INNOVA 3100, GE Medical Systems, Milwaukee, WI). Local anesthesia was used in two cases due to preexisting cardiac and respiratory dysfunction, while general anesthesia was performed in the remaining 24 cases.

All stent grafts were deployed with the common femoral artery approach via unilateral femoral access. It was not necessary to use conduits for any of the cases. The technical details of TEVAR have been described by Nienaber [13]. Once the true lumen wire access through the left brachial artery was confirmed in the ascending aorta, arch angiography was performed. If imaging indicated the need for left subclavian artery coverage, selective vertebral angiography was performed to evaluate the adequacy of collateral vertebral artery flow and to confirm the absence of internal mammary grafts.

Patients were systemically heparinized with a dosage of $100 \mathrm{IU} / \mathrm{kg}$ by intravenous bolus injection. The delivery

Table 1 Baseline characteristics and CT findings

\begin{tabular}{ll}
\hline Variable & Number (\%) \\
\hline Sex (Male/ Female) & $23 / 3$ \\
Age (y; Mean \pm SD (Range)) & $52.8 \pm 13.1(31-72)$ \\
Descending aorta dimension (mm; Mean \pm SD & $29.0 \pm 2.7(23-36)$ \\
(Range)) & \\
Patients in distance from LSCA to primary tear & \\
$<1.5$ cm & $13(50.0)$ \\
$>1.5$ cm & $13(50.0)$ \\
True lumen appearance & \\
Patent & $20(76.9)$ \\
Severe Stenosis (location) & $2(7.7)$ \\
Thoracic aorta & $1(3.8)$ \\
Common iliac & $1(3.8)$ \\
Occlusion & $4(15.4)$ \\
Abdominal aorta below the renal artery & $1(3.8)$ \\
Common iliac & $3(11.5)$ \\
\hline
\end{tabular}

LSCA- left subclavian artery; ${ }^{\#}$ Diameter decreased more than $80 \%$. system dilator-sheath was advanced into the aortic true lumen, and the stent graft was advanced to completely cover the primary intimal tear. The systolic blood pressure was lowered to less than $100 \mathrm{mmHg}$, and the heart rate was lowered to below 90 beats $/ \mathrm{min}$. In order to exclude false lumen flow, the stent graft was delivered under fluoroscopic guidance to cover the primary intimal tear. Ballooning of the stent graft was performed only if a large type Ia proximal endoleak was documented, and ballooning occurred only at the proximal landing zone. When needed, a second stent graft was placed. Angiography confirmed the absence of endoleaks and determined the perfusion status of the previously ischemic arterial beds. Technical success was determined by exclusion of proximal primary entry flap on the completion angiogram. The details of TEVAR procedures are listed in Table 2.

ACBD patients with severe end-organ malperfusion who underwent TEVAR were administered prophylactic hemodialysis. In the case of ACBD with severe malperfusion, the important organs affected were the kidney, the intestine and the lower extremities. Severe end-organ malperfusion was empirically defined as the appearance

\section{Table 2 TEVAR procedure characteristics}

\begin{tabular}{|c|c|}
\hline Variable & Number (\%) \\
\hline \multicolumn{2}{|l|}{$\begin{array}{l}\text { Time interval between symptom onset and } \\
\text { procedure }\end{array}$} \\
\hline (d; Mean \pm SD (Range)) & $7.8 \pm 4.4(1-14)$ \\
\hline \multicolumn{2}{|l|}{$\begin{array}{l}\text { Stent graft oversizing aorta diameter of landing } \\
\text { zone }\end{array}$} \\
\hline $10 \%$ & $20(76.9)$ \\
\hline $15 \%$ & $4(15.4)$ \\
\hline $20 \%$ & $2(7.7)$ \\
\hline \multicolumn{2}{|l|}{ Size of the stent graft ${ }^{\#}(\mathrm{~mm}$; mean $\pm \mathrm{SD}$ (Range)) } \\
\hline Proximal diameter & $33.7 \pm 3.6(28-40)$ \\
\hline Distal diameter & $33.4 \pm 3.8(28-40)$ \\
\hline Graft length & $\begin{array}{l}127.6 \pm 29.2(60- \\
162)\end{array}$ \\
\hline \multicolumn{2}{|l|}{ Coverage of branch artery } \\
\hline LSCA coverage & $9(34.6)$ \\
\hline LSCA dominant & $2(7.7)$ \\
\hline Aberrant RSCA coverage & $1(3.8)$ \\
\hline LCCA coverage & $2(7.7)$ \\
\hline Partial LCCA coverage & $1(3.8)$ \\
\hline Length of aorta covered ( $\mathrm{cm}$; mean $\pm \mathrm{SD}$ (Range)) & $13.5 \pm 2.9(6-18)$ \\
\hline Operation time ( $h$; mean \pm SD (Range)) & $2.2 \pm 1.1(1-6.4)$ \\
\hline Contrast volume (ml; mean \pm SD (Range)) & $\begin{array}{l}190 \pm 61.2(100- \\
350)\end{array}$ \\
\hline
\end{tabular}

LSCA- left subclavian artery; RSCA- right subclavian artery; LCCA- left common carotid artery.

\# Two stent grafts were implanted in one patient. 
of any one of following indicators: Type II extremity ischemia [14], intestine malperfusion related hematochezia or hematemesis, blood creatinine level $\geq 500 \mu \mathrm{mol} / \mathrm{L}$, or blood creatine kinase $\geq 10000 \mathrm{IU} / \mathrm{L}$. According to empirical indicators of the severe end-organ malperfusion, patients with more than two indicators were administered prophylactic hemodialysis after TEVAR.

\section{Data collection and statistical analysis}

Data collected included age, survival status, graft components utilized, access arteries, subclavian artery coverage, length of in-hospital stay, major/minor in-hospital complications, and status of the false lumen immediately after procedure. Major complications were defined as events that were life threatening or would prompt major therapeutic consequences (e.g., access complications requiring surgical revision, re-interventional treatment or requiring dialysis). Minor complications were defined as that no further treatment was required (e.g., transient renal failure not requiring dialysis or transient spinal cord ischemia).

This was a retrospective, non-comparative analysis. All statistical data were descriptive on an intent-to-treat basis. Discrete variables were presented as percentages, while continuous variables were presented as counts and are presented as mean $\pm \mathrm{SD}$. The ethical approval for this study was provided by the Ethical Committee of the Chinese PLA General Hospital.

\section{Results}

\section{Procedural data}

Symptomatic indications for intervention included persistent pain (23 patients), malperfusion (10 patients), aortic failure (8 patients), and refractory hypertension (5 patients). Multiple indicators were present in 16 patients (Table 3 ).

\section{Table 3 Indicators for TEVAR}

\begin{tabular}{ll}
\hline Indications & $\mathbf{n}$ \\
\hline Malperfusion & $10(38.5 \%)$ \\
Lower extremity ischemia & 4 \\
Paraplegia & 2 \\
Renal artery malperfusion & 7 \\
SMA malperfusion & 6 \\
Refractory hypertension/ encephalopathy & $5 / 2(19.2 \%)$ \\
Persistent Pain & $23(88.5 \%)$ \\
Chest pain & 14 \\
Abdominal pain & 16 \\
Aortic failure & $8(30.8 \%)$ \\
Acute true lumen collapse & 3 \\
Severe pleural effusion & 6 \\
\hline
\end{tabular}

Twelve patients had two indications and four patients had three indications. SMA: superior mesenteric artery.
Six types of stent graft systems were used, including Talent (Medtronic Inc, Minneapolis, MN; $\mathrm{n}=11$ ), Valiant (Medtronic Inc, Minneapolis, MN; $\mathrm{n}=8$ ), Zenith (COOK, Inc, Bloomington, IN; $\mathrm{n}=1$ ), Endofit (Endologix Inc, Irvine, CA; $\mathrm{n}=3$ ), Hercules (Microport, Shanghai, China; $\mathrm{n}=4$ ) and Ankura (Lifetech, Shenzhen, China; $\mathrm{n}=2$ ). One stent graft was implanted in 25 patients, and two stent grafts were implanted in one patient to cover multiple tears on the distal descending aorta. The coverage distance between the left common carotiod artery (LCCA) and the primary tear was less than $15 \mathrm{~mm}$ in two patients.

Technical success was achieved in all patients. Delivery system via the femoral approach was successful in all 26 patients, requiring unilateral incision in 24 cases, bilateral femoral incisions in one case, and unilateral incision with contralateral percutaneous access in one case. Immediate postoperative angiography showed no re-entry site at the distal end of the false lumen of six patients with ACBD. The blood supply of visceral arteries via the false lumen was found in the remaining 20 cases.

Twenty patients (77\%) required intensive care unit (ICU) monitoring and continuous intravenous infusion of antihypertensive agents. The average length of hospital stay was $13.8 \pm 9.9$ days (range, 1 to 38 days).

Based on the angiographic findings and patient symptoms, all patients with malperfusion had immediate resolution of the malperfusion deficit after the procedure. Endoleaks were detected in six patients using procedural angiography; five with Type Ia endoleak, in which left subclavian artery was covered in three cases, and one with a Type II endoleak. All patients with endoleaks were untreated in the procedure.

\section{In-hospital deaths and major complications}

Clinical data for the patients who died or had major complications are summarized in Table 4. Four patients died and four patients experienced major complications following TEVAR. In these patients, the average length of stay in the ICU was $12.9 \pm 9.8$ days (range, 0 to 29 days) after the procedure. Three deaths were attributed to pre-existing organ malperfusion and ischemia reperfusion injury (IRI), and one was attributed to RF, respiratory infection, and renal failure (Table 4). An independent Clinical Events Committee adjudicated that all deaths were not related to the TEVAR procedure itself.

In six patients with SMA malperfusion and a bloody stool, two died and one had a major complication after the procedure. Of the other three patients, all survived without any symptoms of intestinal ischemia. In four patients with lower extremity malperfusion, two patients had Type III ischemic mottling who died after the procedure. One patient had no pulse, pallor, and paresthesia, but he survived once the lower extremity 
Table 4 Patient outcomes

\begin{tabular}{|c|c|c|c|c|c|c|c|c|}
\hline Outcome & Sex/ Age & $\begin{array}{c}\text { Clinical } \\
\text { indications }\end{array}$ & $\begin{array}{l}\text { Indicators of } \\
\text { severe end- } \\
\text { organ } \\
\text { malperfusion } \\
\text { (number) }\end{array}$ & $\begin{array}{l}\text { Cause of death } \\
\text { or major } \\
\text { complication }\end{array}$ & $\begin{array}{l}\text { Malperfused } \\
\text { branch } \\
\text { arteries } \\
\text { before } \\
\text { procedure }\end{array}$ & $\begin{array}{c}\text { Onset } \\
\text { time to } \\
\text { procedure }\end{array}$ & $\begin{array}{l}\text { Malperfused } \\
\text { branch arteries } \\
\text { after procedure }\end{array}$ & $\begin{array}{l}\text { Length of stay } \\
\text { post procedure }\end{array}$ \\
\hline Death & M/ 58 & $\begin{array}{l}\text { Abdominal pain, } \\
\text { paraplegia, } \\
\text { bilateral low } \\
\text { extremity } \\
\text { ischemic mottling } \\
\text { (type III) }{ }^{\text {a }} \text {, arterial } \\
\text { hypertension }\end{array}$ & 3 & IRI, MOF & $\begin{array}{l}\text { Occlusion of } \\
\text { bilateral RA } \\
\text { and infrarenal } \\
\text { aorta true } \\
\text { lumen } \\
\text { collapse }\end{array}$ & $48 \mathrm{~h}$ & $\begin{array}{l}\text { Open of left RA } \\
\text { (double lumen } \\
\text { supply), right RA } \\
\text { (false lumen } \\
\text { supply) and } \\
\text { infrarenal aorta } \\
\text { (true lumen } \\
\text { supply) }\end{array}$ & $9 \mathrm{~d}(\mathrm{ICU} 9 \mathrm{~d})$ \\
\hline Death & M/ 39 & $\begin{array}{c}\text { Abdominal pain, } \\
\text { hematochezia, } \\
\text { hematemesis }\end{array}$ & 3 & $\mid \mathrm{RI}, \mathrm{MOF}$ & $\begin{array}{c}\text { Occlusion of } \\
\text { SMA, bilateral } \\
\text { RA }\end{array}$ & $15 \mathrm{~h}$ & $\begin{array}{l}\text { Open of bilateral } \\
\text { RA (true lumen } \\
\text { supply), SMA } \\
\text { dissection }\end{array}$ & $2 \mathrm{~d}(\mathrm{ICU} 2 \mathrm{~d})$ \\
\hline Death & M/ 31 & $\begin{array}{c}\text { Abdominal pain, } \\
\text { hematochezia, left } \\
\text { low extremity } \\
\text { ischemic pallor } \\
\text { and suggillation } \\
\text { (type III), arterial } \\
\text { hypertension }\end{array}$ & 3 & $\begin{array}{l}\text { IRI, Intestinal tract } \\
\text { necrosis }\end{array}$ & $\begin{array}{l}\text { Occlusion of } \\
\text { SMA, right RA } \\
\text { and right CIA }\end{array}$ & $13 \mathrm{~h}$ & $\begin{array}{l}\text { Open of SMA, } \\
\text { right RA and } \\
\text { right CIA (true } \\
\text { lumen supply) }\end{array}$ & $7 \mathrm{~h}(\mathrm{ICU} 7 \mathrm{~h})$ \\
\hline Death & M/ 61 & $\begin{array}{c}\text { Arterial } \\
\text { hypertension, } \\
\text { encephalopathy }\end{array}$ & no & $\begin{array}{l}\text { ARDS, renal failure, } \\
\text { respiratory } \\
\text { infection, } \\
\text { encephalopathy }\end{array}$ & None & $8 d$ & None & $29 \mathrm{~d}($ ICU $29 \mathrm{~d})$ \\
\hline Live & M/ 65 & $\begin{array}{l}\text { Chest pain, arterial } \\
\text { hypertension }\end{array}$ & no & $\begin{array}{l}\text { ARDS, acute } \\
\text { hepatic failure, } \\
\text { respiratory } \\
\text { infection }\end{array}$ & None & $52 \mathrm{~h}$ & None & $31 \mathrm{~d}$ (ICU 24d) \\
\hline Live & $M / 41$ & Tar stool & 2 & $\begin{array}{l}\text { ARDS, respiratory } \\
\text { infection, } \\
\text { hydropericardium, } \\
\text { pleural effusion }\end{array}$ & $\begin{array}{l}\text { Occlusion of } \\
\text { right RA and } \\
\text { CIA }\end{array}$ & $11 \mathrm{~d}$ & $\begin{array}{l}\text { Open of right RA } \\
\text { and CIA (true } \\
\text { lumen supply) }\end{array}$ & $12 \mathrm{~d}(\mathrm{ICU} 11 \mathrm{~d})$ \\
\hline Live & M/ 32 & $\begin{array}{l}\text { Obesity, pleural } \\
\text { effusion }\end{array}$ & no & $\begin{array}{l}\text { ARDS, Respiratory } \\
\text { infection }\end{array}$ & None & $7 d$ & None & $34 \mathrm{~d}$ (ICU 16d) \\
\hline Live & F/ 39 & $\begin{array}{l}\text { Abdominal pain, } \\
\text { hematochezia }\end{array}$ & 2 & $\begin{array}{c}\text { Intestinal ischemia, } \\
\text { intestinal infection, } \\
\text { ischemic } \\
\text { pancreatitis }\end{array}$ & $\begin{array}{c}\text { Occlusion of } \\
\text { SMA, right RA } \\
\text { and left EIA }\end{array}$ & $4 d$ & $\begin{array}{l}\text { Open of SMA, } \\
\text { right RA and left } \\
\text { EIA (true lumen } \\
\text { supply) }\end{array}$ & $38 \mathrm{~d}(\mathrm{ICU} 11 \mathrm{~d})$ \\
\hline
\end{tabular}

RA, renal artery; SMA, superior mesenteric artery; CIA, common iliac artery; MOF, multiple organ failure; ARDS, adult respiratory distress syndrome; EIA, external iliac artery; IRI, ischemic reperfusion injury. ${ }^{\text {T}}$ The classification of low extremity ischemia was from reference 14.

malperfusion was relieved. In seven patients with renal malperfusion before the procedure, only one patient had renal dysfunction after the procedure. Three patients with three indicators of severe end-organ malperfusion died even though hemodialysis was administered after TEVAR (Table 4).

In four patients with major complications after the procedure, three had RF and respiratory infection. Another patient had pre-existing organ malperfusion and IRI. In four patients with RF after the procedure, the duration of tracheal intubation was $20 \pm 7.8$ days (range, 11 to 29). Only one patient had severe pleural effusion before the procedure. In six patients with severe pleural effusion after the procedure, five accepted tracheal extubation immediately after the procedure, while one patient with tracheal intubation for 16 days had RF and respiratory infection.

Two patients had minor complications. One patient had a headache that resolved five days after the procedure. The other patient had right low extremity malperfusion and transient renal failure, but recovered one week after the procedure without the need for dialysis. In 23 patients with persistent chest or abdominal pain before the procedure, three died from malperfusion and IRI, while three of the survivors had persistent chest and abdominal pain that was unrelieved. In five patients with refractory hypertension before the procedure, one died. Of the remaining four survivors, three patients had refractory hypertension that resolved on its own. Except for one pre-procedural paraplegia patient, none of the 
surviving patients had complications requiring further treatment at the time of hospital discharge.

\section{Follow-up data}

All 22 in-hospital live patients were followed up from 1 to 49 months (average, $6.8 \pm 7.3$ months). The type Ia endoleak in 4 patients spontaneous resolved at one month. The endoleaks in another 2 patients ( 1 with type Ia and 1 with type II) were observed at three month. Two deaths occurred at 2 and 3 months and the reasons were unclear. One late deaths was as the result of pulmonary carcinoma at 24 months.

\section{Discussion}

Both dissection rupture or imminent rupture and malperfusion are indicators for emergency TEVAR in a patient with ACBD [15]. In fact, imminent rupture is difficult to determine clinically in a patient with ACBD, and dissection rupture is more rare than malperfusion $[9,15,16]$. The most significant findings of this study were that in-hospital mortality associated with severe end-organ malperfusion IRI and major complications associated with RF during TEVAR.

There were 10 patients (38.5\%) with malperfusion in our group; however, no patients showed evidence of dissection rupture or imminent rupture. In previous singlecenter studies, malperfusion was a common indicator among patients (Table 5). Before our study, the poor prognosis of malperfusion had not been systematically analyzed. Compared with other indicators, including refractory hypertension, persistent pain and aorta failure, malperfusion is a more urgent indicator for emergency TEVAR. This is due to the fact that end-organ malperfusion and subsequent life-threatening organ failure are imminent results. In addition, the severity of ACBD malperfusion and IRI appear to be more closely related to early mortality following TEVAR than the other complications.

After TEVAR, the malperfused end-organ artery may open causing early IRI. Irreversible malperfusion and early IRI can increase the systemic absorption of metabolic toxins, which may become a direct cause of multiple organ

Table 5 Malperfusion proportion in ACBD patients

\begin{tabular}{lccc}
\hline Study & Malperfusion (n) & ACBD (n) & Proportion \\
\hline Szeto [4] & 17 & 35 & 48.6 \\
Feezor [6] & 11 & 33 & 33.3 \\
Conrad [7] & 17 & 33 & 51.5 \\
Parsa [12] & 11 & 22 & 50 \\
Pearce [15] & 8 & 15 & 53.3 \\
Khoynezhad [16] & 15 & 28 & 53.6 \\
Botsios [17] & 6 & 32 & 18.8 \\
\hline
\end{tabular}

$\mathrm{ACBD}=$ acute complicated type $\mathrm{B}$ aortic dissection. failure and death after TEVAR. If end-organ malperfusion is more serious, then the IRI will be more serious after TEVAR and early mortality will consequently be higher. In-hospital mortality following TEVAR occurred in three of the 10 patients with malperfusion and accounted for three of four $(75 \%)$ in-hospital deaths. In similar singlecenter studies, Pearce [16] and Szeto [4] reported a higher proportion of malperfusion (Table 5), but no malperfusionrelated mortality. In other similar two single-center studies, Khoynezhad [17] and Feezor [6] reported a higher proportion of malperfusion (Table 5) and significant malperfusion-related mortality rates $(7 \%$ and $13.3 \%$, respectively). In our study, the three malperfusion-related deaths occurred in patients who had severe malperfusion and IRI of one or two end-organs. In studies by Pearce [16], Szetodl [4], Khoynezhad [17] and Feezor [6], information regarding the degree of end-organ ischemia was not included. Classification of the degree of end-organ malperfusion would help predict the mortality rate after TEVAR.

In the process of TEVAR, many surgeons use surgical or interventional fenestration $[18,19]$ or branch vessel stenting [6] to handle persistent malperfusion. There are few reports about the process of IRI in malperfusion with an open end-organ artery.

In our study, three of five ACBD patients with severe malperfusion suffered IRI, multiple organ failure, and in-hospital death even though they received prophylactic hemodialysis post-TEVAR. We found that the clearance of metabolic toxins was poor in improving survival of severe malperfusion ACBDs. For these patients, removal of severe malperfusion end-organs may be acquired more beneficial than re-opening the end-organ artery. Currently, more published reports of ACBD have been concerned how to reopen malperfusion end-organ arteries in TEVAR [3,6,15,20-24]. Fenestration and stenting have been used frequently, and prosthetic bypass has been used in visceral malperfusion.

There are few reports detailing when malperfusion persists to result in end-organ ischemia, nor are there any reports regarding the assessment of the degree of end-organ malperfusion, IRI severity and reversibility of malperfusion end-organ function in TEVAR therapy. In our study, the cause of three ACBD patient deaths were malperfusion and IRI, who had more than two indicators of severe end-organ malperfusion (Table 4). On the other hand, two malperfusion ACBD patients who survived had only two indicators (Table 4). The other five malperufsion ACBD patients who survived had no indicators of severe end-organ malperfusion. Re-opening the malperfusion artery is not a unique option. We propose that nonreversible end-organ malperfusion is an indication for primary surgical removal of end-organs (e.g., extremity amputation, intestine resection). Some centers have reported a little experience of organ resection, but 
the organ removal indicators, primary surgical risk and postoperative prognosis is still unknown [9,21]. Our study suggests that a number of indicators of severe end-organs malperfusion could become the basis of malperfusion organ removal or malperfusion organ artery re-opening.

RF occurred postoperatively in four patients, including one who died. The cause of postoperative RF was not clear because these patients had no pulmonary disease or severe malperfusion, with the exception of one patient who had preoperative pleural effusion and obesity. In regards to the possible causes of respiratory failure, it has been reported that ischemia and reperfusion of intestine, renal, and lower extremity may cause distant pulmonary injury. Feezor et a.l [6] reported that 11 of 33 ACBD patients who underwent emergency TEVAR suffered RF without any apparent underlying cause. Additionally, Sachs [25] showed respiratory complications accounted for $4.3 \%$ of type B dissections after TEVAR. Kurabayashi [26] demonstrated that the only independent predictor of oxygenation impairment was acute aortic dissection (odds ratio, 1.323; 95\% confidence interval, 1.035-1.691, $\mathrm{P}=0.026$ ). This study proposed that $\mathrm{RF}$ in acute aortic dissection closely correlated with aortic injury, possibly mediated by the magnitude of the systemic inflammatory reaction to the aortic injury. Eggebrecht [27] quantified inflammatory markers in patients who underwent TEVAR and found that post-procedural inflammatory responses were more pronounced and correlated with mortality. Furthermore, it was shown that post-operative RF closely correlated with a systemic inflammatory response syndrome that attacked the lungs. Respiratory infection readily occurred in patients with RF who underwent long-term tracheal intubation.

In our study, the four patients with postoperative RF remained intubated for at least 8 days, and they all developed respiratory infection. Respiratory infection may aggravate RF, which was confirmed in patients with thoracic aortic aneurysm who underwent TEVAR [28]. However, it remains unclear whether the systemic inflammatory response syndrome and respiratory infection induce a malignant cycle that further induces RF. Fortunately, three of the four patients with postoperative RF recovered. Therefore, the etiology of RF after TEVAR and how to prevent it warrants more study.

\section{Conclusions}

This study shows that malperfusion is the more common indicator for ACBD patients to receive emergency TEVAR. The in-hospital mortality of malperfusion ACBD after TEVAR is closely related to malperfusion and IRI. RF is a common major complication of ACBD after TEVAR and may cause respiratory infection. The correlation between RF and systemic inflammation remain to be further understood.

The most effective prevention and treatment of IRI is to restore blood flow as early as possible. Procedures to improve the perfusion to ischemic end-organs should not be delayed only because of fear of reperfusion injury, unless irreversible ischemia has been proved.

\section{Abbreviations}

ACBD: Acute complicated type B aortic dissection; TEVAR: Thoracic endovascular aortic repair; IRI: Ischemia reperfusion injury; RF: Respiratory failure; CT: Computed tomography; LCCA: Left common carotiod artery; ICU: Intensive care unit.

\section{Competing interests}

The authors declare that they have no competing interests.

\section{Authors' contributions}

JX and WG carried out the conception and design. JX, MZ and WG carried out the analysis and interpretation. JX, MZ, XL, TY, XJ, HZ, YX and LW participated in the data collection. JX participated in the writing the article, the critical revision of the article and the statistical analysis. All authors read and approved the final manuscript.

Received: 1 September 2012 Accepted: 8 January 2013

Published: 23 January 2013

\section{References}

1. Fattori R, Tsai TT, Myrmel T, Evangelista A, Cooper JV, Trimarchi S, Li J, Lovato L, Kische S, Eagle KA, Isselbacher EM, Nienaber CA: Complicated acute type $B$ dissection: is surgery still the best option?: a report from the international registry of acute aortic dissection. JACC Cardiovasc Interv 2008, 1:395-402.

2. Dake MD, Kato N, Mitchell RS, Semba CP, Razavi MK, Shimono T, Hirano T, Takeda K, Yada I, Miller DC: Endovascular stent-graft placement for the treatment of acute aortic dissection. N Engl J Med 1999, 340:1546-1552.

3. Ehrlich MP, Dumfarth J, Schoder M, Gottardi R, Holfeld J, Juraszek A, Dziodzio T, Funovics M, Loewe C, Grimm M, Sodeck G, Czerny M: Midterm results after endovascular treatment of acute, complicated type B aortic dissection. Ann Thorac Surg 2010, 90:1444-1448.

4. Szeto WY, McGarvey M, Pochettino A, Moser GW, Hoboken A, Cornelius K, Woo EY, Carpenter JP, Fairman RM, Bavaria JE: Results of a new surgical paradigm: endovascular repair for acute complicated type B aortic dissection. Ann Thorac Surg 2008, 86:87-94.

5. Roseborough G, Burke J, Sperry J, Perler B, Parra J, Williams GM: Twentyyear experience with acute distal thoracic aortic dissections. J Vasc Surg 2004, 40:235-246.

6. Feezor RJ, Martin TD, Hess PJ Jr, Beaver TM, Klodell CT, Lee WA: Early outcomes after endovascular management of acute, complicated type B aortic dissection. J Vasc Surg 2009, 49:561-567.

7. Conrad MF, Crawford RS, Kwolek CJ, Brewster DC, Brady TJ, Cambria RP: Aortic remodeling after endovascular repair of acute complicated type B aortic dissection. J Vasc Surg 2009, 50:510-517.

8. Manning BJ, Dias N, Manno M, Ohrlander T, Malina M, Sonesson B, Resch T, Ivancev K: Endovascular treatment of acute complicated type $B$ dissection: morphological changes at midterm follow-up. J Endovasc Ther 2009, 16:466-474

9. Schoder M, Czerny M, Cejna M, Rand T, Stadler A, Sodeck GH, Gottardi R, Loewe C, Lammer J: Endovascular repair of acute type B aortic dissection: long-term follow-up of true and false lumen diameter changes. Ann Thorac Surg 2007, 83:1059-1066.

10. Cambria RP, Crawford RS, Cho JS, Bavaria J, Farber M, Lee WA, Ramaiah V, Kwolek CJ, GORE TAG Investigators: A multicenter clinical trial of endovascular stent graft repair of acute catastrophes of the descending thoracic aorta. J Vasc Surg 2009, 50:1255-1264. e1-4.

11. Xu SD, Huang FJ, Yang JF, Li ZZ, Wang XY, Zhang ZG, Du JH: Endovascular repair of acute type $B$ aortic dissection: early and mid-term results. J VasC surg 2006, 43:1090-1095. 
12. Parsa CJ, Schroder JN, Daneshmand MA, McCann RL, Hughes GC: Midterm results for endovascular repair of complicated acute and chronic type $B$ aortic dissection. Ann Thorac Surg 2010, 89:97-104.

13. Nienaber CA, Zannetti S, Barbieri B, Kische S, Schareck W, Rehders TC, INSTEAD study collaborators: INvestigation of STEnt grafts in patients with type B Aortic Dissection: design of the INSTEAD trial-a prospective, multicenter, European randomized trial. Am Heart J 2005, 149:592-599.

14. Rutherford RB, Baker JD, Ernst C, Johnston KW, Porter JM, Ahn S, Jones DN: Recommended standards for reports dealing with lower extremity ischemia: revised version. J Vasc Surg 1997, 26:517-538.

15. Moon MC, Pablo Morales J, Greenberg RK: Complicated acute type B dissection and endovascular repair: indications and pitfalls. Perspect VasC Surg Endovasc Ther 2007, 19:146-159.

16. Pearce BJ, Passman MA, Patterson MA, Taylor SM, Lecroy CJ, Combs BR, Jordan WD: Early outcomes of thoracic endovascular stent-graft repair for acute complicated type B dissection using the Gore TAG endoprosthesis. Ann Vasc Surg 2008, 22:742-749.

17. Khoynezhad A, Donayre CE, Omari BO, Kopchok GE, Walot I, White RA: Midterm results of endovascular treatment of complicated acute type $B$ aortic dissection. J Thorac Cardiovasc Surg 2009, 138:625-631.

18. Trimarchi $\mathrm{S}$, Jonker FH, Muhs BE, Grassi V, Righini P, Upchurch GR, Rampoldi $V$ : Long-term outcomes of surgical aortic fenestration for complicated acute type B aortic dissections. J Vasc Surg 2010, 52:261-266.

19. Sharif MA, O'Donnell ME, Blair PH, Kennedy P: Emergency endovascular repair of acute descending thoracic aortic dissection. Vasc Health Risk Manag 2007, 3:769-773.

20. Botsios S, Schuermann K, Maatz W, Keck N, Walterbusch G: Complicated acute type $B$ dissections: a single-center experience with endovascular treatment. Thorac Cardiovasc Surg 2010, 58:280-284.

21. Verhoye JP, Miller DC, Sze D, Dake MD, Mitchell RS: Complicated acute type B aortic dissection: midterm results of emergency endovascular stent-grafting. J Thorac Cardiovasc Surg 2008, 136:424-430.

22. Karmy-Jones R, Simeone A, Meissner M, Granvall B, Nicholls S: Descending thoracic aortic dissections. Surg Clin North Am 2007, 87:1047-1086.

23. Duebener L, Hartmann F, Kurowski V, Richardt G, Geist V, Erasmi A, Sievers $\mathrm{HH}$, Misfeld M: Surgical interventions after emergency endovascular stent-grafting for acute type B aortic dissections. Interact Cardiovasc Thorac Surg 2007, 6:288-292.

24. Bastos Gonçalves F, Metz R, Hendriks JM, Rouwet EV, Muhs BE, Poldermans $D$, Verhagen HJ: Decision-making in type-B dissection: current evidence and future perspectives. J Cardiovasc Surg (Torino) 2010, 51:657-667.

25. Sachs T, Pomposelli F, Hagberg R, Hamdan A, Wyers M, Giles K, Schermerhorn M: Open and endovascular repair of type B aortic dissection in the nationwide inpatient sample. J Vasc Surg 2010, 52:860-866

26. Kurabayashi M, Okishige K, Azegami K, Ueshima D, Sugiyama K, Shimura T, Maeda M, Aoyagi $\mathrm{H}$, Isobe M: Reduction of the PaO2/FiO2 ratio in acute aortic dissection - relationship between the extent of dissection and inflammation. Circ J 2010, 74:2066-2073.

27. Eggebrecht $\mathrm{H}$, Mehta RH, Metozounve H, Huptas S, Herold U, Jakob HG, Erbel R: Clinical implications of systemic inflammatory response syndrome following thoracic aortic stent-graft placement. J Endovasc Ther 2008, 15:135-143.

28. Ishida M, Kato N, Hirano T, Cheng SH, Shimono T, Takeda K: Endovascular stent-graft treatment for thoracic aortic aneurysms: short- to midterm results. J Vasc Interv Radiol 2004, 15:361-367.

doi:10.1186/1749-8090-8-17

Cite this article as: Xiong et al:: Early malperfusion, ischemia reperfusion injury, and respiratory failure in acute complicated type B aortic dissection after thoracic endovascular repair. Journal of Cardiothoracic Surgery 2013 8:17.

\section{Submit your next manuscript to BioMed Central and take full advantage of:}

- Convenient online submission

- Thorough peer review

- No space constraints or color figure charges

- Immediate publication on acceptance

- Inclusion in PubMed, CAS, Scopus and Google Scholar

- Research which is freely available for redistribution

Submit your manuscript at www.biomedcentral.com/submit
Ciomed Central 